Canadian

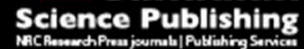

Canadian Journal of Chemistry Revue canadienne de chimie

\title{
Hydrogen Evolution at Conjugated Polymer Nanoparticle Electrodes
}

\begin{tabular}{|c|c|}
\hline Journal: & Canadian Journal of Chemistry \\
\hline Manuscript ID & cjc-2017-0329.R1 \\
\hline Manuscript Type: & Article \\
\hline Date Submitted by the Author: & 24-Jul-2017 \\
\hline Complete List of Authors: & $\begin{array}{l}\text { Fortin, Patrick; Simon Fraser University, Chemistry } \\
\text { Rajasekar, Subash; Simon Fraser University, Chemistry } \\
\text { Chowdhury, Pankaj; Simon Fraser University, Chemistry } \\
\text { Holdcroft, Steve; Simon Fraser University }\end{array}$ \\
\hline $\begin{array}{r}\text { Is the invited manuscript for } \\
\text { consideration in a Special } \\
\text { Issue?: }\end{array}$ & SFU \\
\hline Keyword: & $\begin{array}{l}\text { water splitting, hydrogen evolution, photoelectrochemistry, organic } \\
\text { polymers, nanoparticles }\end{array}$ \\
\hline
\end{tabular}

\section{SCHOLARONE \\ Manuscripts}




\title{
Hydrogen Evolution at Conjugated Polymer Nanoparticle Electrodes
}

Patrick Fortin, Subash Rajasekar, Pankaj Chowdhury and Steven Holdcroft *

Department of Chemistry, Simon Fraser University, Burnaby, BC, Canada V5A 1S6

* To whom correspondence should be addressed. E-mail: holdcrof@sfu.ca

Keywords: water splitting, hydrogen evolution, photoelectrochemistry, organic polymers, nanoparticles

\begin{abstract}
Organic polymer nanoparticles have been gaining attention in photovoltaics as a means to control the morphology of polymer composite films for the purpose of studying bulk heterojunction, photoactive layers. This work investigates the preparation of nanostructured organic thin films from $\mathrm{P} 3 \mathrm{HT}: \mathrm{PC}_{61} \mathrm{BM}$ nanoparticles and their characterization as photoelectrodes for the photoelectrochemical reduction of hydrogen in acidic solutions. The morphology and optoelectronic properties of the nanostructured photocathodes are compared to conventional, solution-cast thin films of $\mathrm{P} 3 \mathrm{HT}: \mathrm{PC}_{61} \mathrm{BM}$. The nanostructured photoelectrodes provide increased surface area compared to solution-cast films through control of the nanoscale morphology within each nanoparticle, leading to enhanced $\mathrm{P} 3 \mathrm{HT}: \mathrm{PC}_{61} \mathrm{BM}$ phase segregation. The photo-assisted deposition of platinum nanoparticles as hydrogen evolution reaction (HER) catalysts onto the nanostructured $\mathrm{P} 3 \mathrm{HT}: \mathrm{PC}_{61} \mathrm{BM}$ photocathodes facilitates the photoreduction of protons to $\mathrm{H}_{2}$.

\section{Introduction}

Over the past two decades, organic photovoltaic (OPV) devices have generated much interest as solar energy conversion efficiencies for single junction solar cells have exceeded $10 \% ;^{1-4}$ while efficiencies of multi-junction cells have exceeded $13 \%{ }^{5}$ Moreover, growing attention is being paid to the investigation of organic $\pi$-conjugated polymers as photocathodes in solar-driven water splitting devices. Photoelectrochemical (PEC) water splitting is considered by many to be a clean, sustainable and viable method of hydrogen production. ${ }^{6}$ Whereas significant research efforts have been devoted to PEC water splitting using inorganic 
photoelectrodes, ${ }^{7-9}$ there are considerably fewer reports of the exploration photoelectrochemical water splitting at organic-based electrodes. The operation of an organic photoelectrochemical cell consisting of a polymer:fullerene active layer can be viewed as a four step process, illustrated in figure 1: 1) Photon absorption - where a photon with energy greater than or equal to the polymer band gap is absorbed, in turn exciting an electron in the highest occupied molecular orbital (HOMO) of the polymer to the lowest unoccupied molecular orbital (LUMO). This creates a coulombically bound electron-hole pair known as an exciton. 2) Charge transfer at the polymer:fullerene interface - where the photoexcited exciton separates into its constituent charges, with the electron being transferred into the fullerene domain and the hole remaining within the polymer domain. 3) Charge migration - where the separated charges percolate through the active layer to their respective interfaces. The vast majority or organic polymers are $\mathrm{p}$-type semiconductors, therefore electrons in the fullerene domain migrate towards the active layer/electrolyte interface and holes residing in the polymer migrate towards the active layer/substrate interface. 4) Electrochemical processes - where the separated charges are used at their respective interfaces. At the working electrode (polymer:fullerene photocathode), photoexcited electrons are used to reduce hydrated protons in the electrolyte to hydrogen gas. To balance this process, a counter electrode is used, where water is oxidized to oxygen gas and protons. The electrons withdrawn at the counter electrode as a result of water oxidation travel through the external circuit and recombine with the holes, from the polymer domain, at the active layer/substrate interface, thus completing the circuit. The aqueous photoelectrochemical activity of organic semiconducting polymers was demonstrated with poly(3-hexylthiophene) (P3HT) two decades ago. ${ }^{10}$ Subsequent reports of 
organic polymer photoelectrochemical cells remained relatively dormant until 2012, when Lanzarini et al. described the photocathodic activity of $\mathrm{P} 3 \mathrm{HT}: \mathrm{PC}_{61} \mathrm{BM}$ bulk heterojunction layers in aqueous $\mathrm{NaCl}^{11}$ Researchers have since incorporated hydrogen evolution catalysts such as $\mathrm{Pt}^{12,13}$ and $\mathrm{MoS}_{3}{ }^{14}$ into the device architecture in order to increase the rate of photoelectrochemical hydrogen evolution. The introduction of interfacial transport layers in combination with these HER catalysts has also been shown to improve electrochemical charge transfer. ${ }^{15-18}$ Photocurrent densities produced by irradiation of organic photoelectrodes have therefore progressively increased from sub- $\mu \mathrm{A} / \mathrm{cm}^{2}$ values to milliamps $/ \mathrm{cm}^{2}$ in just a few years. Several of the hole transport layers (HTL) used in organic photoelectrochemical devices to promote unidirectional flow of electrical charges, such as PEDOT:PSS, ${ }^{14} \mathrm{MoO}_{3}{ }^{18}$ and $\mathrm{Cul},{ }^{19}$ have been deposited from solution. Photocurrents as high as $8 \mathrm{~mA} / \mathrm{cm}^{2}$ at $0 \mathrm{~V}$ (RHE) have been reached with a device architecture consisting of a solution-processed Cul hole transport layer on an indium-doped tin oxide (ITO) substrate, a $\mathrm{P} 3 \mathrm{HT}: \mathrm{PC}_{61} \mathrm{BM}$ active layer, a $\mathrm{TiO}_{2}$ electron transport layer deposited by pulsed laser deposition, a sputtered Pt catalyst layer, and a polyethyleneimine protective coating. ${ }^{19}$ The increased photocurrent densities attained through engineering of interfacial layers have, therefore, come at the expense of added complexity of the device fabrication process and the need for vacuum-deposition techniques. However, Bourgeteau et al. recently described a fully solution-processed organic photocathode with a device architecture of ITO/MoO $/ \mathrm{P} 3 \mathrm{HT}: \mathrm{PC}_{61} \mathrm{BM} / \mathrm{MoS}_{3}$ capable of achieving stable photocurrent densities of $2 \mathrm{~mA} / \mathrm{cm}^{2}$ at $0 \mathrm{~V}(\mathrm{RHE})$ for one hour. ${ }^{20}$

A strategy often adopted in inorganic photoelectrode materials chemistry for increasing photocurrent density, and hence photoefficiency, is to increase the surface area of the 
electrode by way of forming a nanostructured electrode surface, as demonstrated with a range of nanostructured semiconductor photoelectrodes, each of which offer distinct improvements. For instance, high aspect ratio nanowire electrodes are able overcome charge transport constraints of planar electrodes by minimizing the exciton diffusion path length to the semiconductor/electrolyte interface, so that photogenerated holes and electrons can be efficiently separated prior to their recombination. ${ }^{21}$ Nanoholes have been integrated into 20 $\mu \mathrm{m}$-thin Si electrodes and decorated with Pt nanoparticle catalysts. ${ }^{22}$ The high photocurrent densities achieved using these structures $\left(23 \mathrm{~mA} / \mathrm{cm}^{2}(\mathrm{RHE})\right.$ is attributed to the antireflective properties of the nanoholes, which increases light absorption in the thin electrodes, as well as increasing the charge transfer kinetics due to suppression of surface recombination. Recently, nonprecious-metal catalysts were deposited onto pyramidally, nanotextured silicon substrates, ${ }^{23}$ and the enhanced interfacial electrode area used to increase the amount of catalytic sites accessible for the hydrogen evolution reaction, yielding photocurrents of $12 \mathrm{~mA} / \mathrm{cm}^{2}$.

Organic semiconducting polymers have the distinct advantage over inorganic counterparts in that they can be cast from simply-prepared polymer solutions. However, when cast, they typically form smooth, uniform films leading to an electrode surface area that is similar to the geometric area of the substrate onto which the film is cast. Drawing from strategies used in the PEC studies of inorganic films it ought to be possible to increase the surface area of the polymer film by adopting a nanoparticle approach to film formation. Nanoparticles of $\mathrm{P} 3 \mathrm{HT}$ and $\mathrm{P} 3 \mathrm{HT}: \mathrm{PC}_{61} \mathrm{BM}$ have indeed been the subject of extensive characterization in recent years as a means to control the morphology of photoactive layers in 
organic photovoltaic light harvesting systems in order to offset the relatively short diffusion length of photogenerated excitons in organic materials. ${ }^{24-29}$ Nanoparticulate systems also allow deposition of photoactive components from water and alcohols rather than from traditional chlorinated solvents, as demonstrated for organic photovoltaic (OPV) ${ }^{30-32}$ and organic field effect transistor (OFET) ${ }^{33}$ devices. Organic polymer and polymer:fullerene nanoparticle dispersions may be prepared by one of two methods: (a) a mini-emulsion method, wherein a polymer or polymer:fullerene blend is dissolved in a solvent and subsequently added to a surfactant-containing non-solvent for which the solvents are immiscible and (b) a surfactantfree precipitation method, in which a polymer or polymer:fullerene blend is dissolved in a solvent and directly injected into a non-solvent, for which the solvent and non-solvent are miscible. Both methods of nanoparticle formation are illustrated in figure 2 .

Although surfactant-stabilized nanoparticles of $\mathrm{P} 3 \mathrm{HT}: \mathrm{PC}{ }_{61} \mathrm{BM}$ have been shown to be smaller than the surfactant-free nanoparticles, ${ }^{34}$ they form core-shell structures, with a $\mathrm{PC}_{61} \mathrm{BM}$-rich core, which may inhibit effective photogenerated charge separation and collection, whereas the surfactant-free precipitation method forms nanoparticles that possess a relatively uniform, blended morphology. ${ }^{35}$ With the surfactant-stabilized nanoparticle approach, trace amounts of surfactant may remain incorporated in the active material and potentially interfere deleteriously with formation of the bulk-heterojunction, and thus impinge upon device performance and device lifetime. ${ }^{32}$ The surfactant-free approach to nanoparticles mitigates these potential issues. In this method, the polymer of choice is dissolved in a "good" solvent and the solution injected, under control, into a "poor" solvent (the non-solvent) so that upon contact with the non-solvent the polymer chains collapse to form spherical-like nanoparticles. 
The concentration of the original polymer solution affects the size of the nanoparticles formed. As the concentration is increased, the number of polymer chains per unit volume is increased, leading to larger nanoparticles. In considering the formation of bulk heterojunction films of donor and acceptor molecules, nanoparticles with the smallest possible diameters are assumed to be preferred for photovoltaic and photoelectrochemical applications in order to minimize the donor and acceptor domain sizes, thereby reducing the exciton diffusion length required to reach the heterojunction interface. Two key variables essential to controlling nanoparticle preparation are: (i) the nature of the solvent and non-solvent, which must be miscible to ensure formation of a homogenous colloidal solution of the polymer; (ii) the concentration of the initial polymer solution, which needs to be low enough so as to form nanoparticles, yet high enough to ensure the colloidal solution formed provides films sufficiently thick so as to be examinable as photocathodes when cast on a substrate. Herein, we report the vacuum-free preparation of high surface area organic photoelectrodes using surfactant-free $\mathrm{P} 3 \mathrm{HT}: \mathrm{PC}_{61} \mathrm{BM}$ nanoparticles (NPs) and the subsequent investigation of their morphological and opto-electronic properties. The influence of these properties on their performance as organic photocathodes, when coupled with a Pt hydrogen evolution catalyst, is investigated and compared to photoelectrodes prepared from solution-cast $\mathrm{P} 3 \mathrm{HT}: \mathrm{PC}_{61} \mathrm{BM}$ films.

\section{Experimental}

Materials - P3HT was purchased from Rieke Metals (MW = 50-70 kg/mol, regioregularity: 91 $94 \%,<0.01 \%$ metal impurities). $\mathrm{PC}_{61} \mathrm{BM}$ (American Dye Sources, Inc.), $\mathrm{K}_{2} \mathrm{PtCl}_{6}$ (Johnson Matthey) and all solvents were all used as-received. All aqueous solutions were prepared using DI water obtained from a Milli-Q water purification system(18M $\Omega$, EMD Millipore). Indium tin 
oxide(ITO) coated glass slides (Merck Display Technologies Ltd.) were cleaned by sequential sonication for 10 minutes in each of the following solutions: dichloromethane, deionized water and isopropyl alcohol. Chemically-cleaned ITO slides were subjected to a plasma treatment using $25 \% \mathrm{O}_{2}$ in Ar for 10 minutes (Fischione Instruments Model 1020 plasma cleaner).

P3HT:PC ${ }_{61} B M$ NP films - Solutions of $\mathrm{P} 3 \mathrm{HT}: \mathrm{PC}_{61} \mathrm{BM}$ was prepared by first dissolving $10 \mathrm{mg}$ of $\mathrm{P} 3 \mathrm{HT}$ in $1 \mathrm{~mL} \mathrm{CHCl}$ and $10 \mathrm{mg}$ of $\mathrm{PC}_{61} \mathrm{BM}$ in $1 \mathrm{~mL} \mathrm{CHCl}$, stirring each overnight at $50{ }^{\circ} \mathrm{C}$. The solutions of $\mathrm{P} 3 \mathrm{HT}$ and $\mathrm{PC}_{61} \mathrm{BM}$ were mixed together and $1.5 \mathrm{~mL}$ of this solution was added by syringe to $4 \mathrm{~mL}$ of isopropyl alcohol (IPA) under sonication at room temperature for 1 minute (Branson 1510 ultrasonic cleaner). A dispersion of nanoparticles of $\mathrm{P} 3 \mathrm{HT}: \mathrm{PC}_{61} \mathrm{BM}$ was obtained, having a final concentration of $2.7 \mathrm{mg} / \mathrm{mL} .100 \mu \mathrm{L}$ aliquots of the NP dispersion were spin-cast onto ITO-coated glass slides at $2000 \mathrm{rpm}$ multiple times to achieve the desired thickness. A film thickness of $\sim 90 \mathrm{~nm}$ required 10 spin-coats.

Deposition of Pt - Pt nanoparticles were photoelectrochemically-deposited onto films of

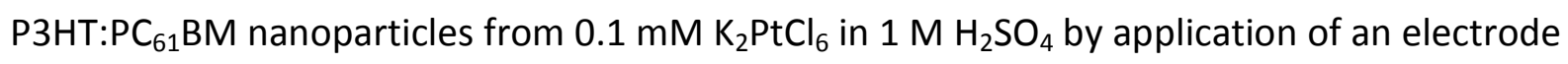
potential of $-0.1 \mathrm{~V}_{\mathrm{SCE}}$ under chopped $\left(100 \mathrm{~mW} \mathrm{~cm}^{-2}\right)$ illumination using 5 second dark and 15 second light intervals for a total irradiation time of $60 \mathrm{~s}$. The amount of Pt deposited on the polymer films was calculated using equation 1:

$m_{P t}=\frac{Q}{n F} * M W_{P t}$

where $\mathrm{m}_{\mathrm{Pt}}$ is the mass of Pt deposited via photoelectrochemical deposition, $\mathrm{Q}$ is the charge passed from the working electrode to the electrolyte and is measured by taking the area above 
the Pt deposition curves, $\mathrm{F}$ is Faraday's constant, $\mathrm{MW}_{\mathrm{Pt}}$ it the molecular weight of $\mathrm{Pt}$ and $\mathrm{n}$, the number of electrons, is 4 .

Photoelectrochemistry - A 200 W Xe/Hg lamp (Uhsio America, inc.) was used in combination with a 300-700 $\mathrm{nm}$ band pass filter (FSQ-KG3, Newport Corp.) and neutral density filters (Thorlabs Inc.), to achieve $100 \mathrm{~mW} \mathrm{~cm}^{-2}$ irradiation, as measured using a broadband power meter (841-PE, Newport Corporation) equipped with an Ophir thermal detector head (3A-PSHV1). A glass photoelectrochemical cell with two large flat windows and five accessory ports was used and the cell configuration was designed to allow irradiation of the polymerelectrolyte interface through the electrolyte. A water filter was placed in front of the electrochemical cell to remove excess heat. Electrochemical measurements were performed using a Pine Bipotentiostat (AFC-BP1). PEC measurements were performed in a 3-electrode configuration using a saturated calomel electrode (SCE) (+0.24 V vs SHE) and a Pt wire as the reference and counter electrodes, respectively. Solutions were purged with nitrogen (Praxair, purity $99.999 \%$ ) for 1 hour in a glass PEC cell and a positive pressure $\mathrm{N}_{2}$ blanket maintained in the overhead volume of the cell. For $\mathrm{H}_{2}$ evolution measurements, the cell was sealed under $\mathrm{N}_{2}$ in order to avoid the loss of any $\mathrm{H}_{2}$ in the head space above the working electrode.

Gas Chromatography - The headspace in the electrochemical cell was sampled using a $5 \mathrm{~mL}$ syringe, fitted with a gastight valve (Series A-2, VICI Precision Sampling), and analyzed using an Agilent Technologies 6890N GC system equipped with a thermal conductivity detector. A $2.13 \mathrm{~m}$ Agilent J\&W GC packed column in stainless steel tubing was used (inner diameter $2 \mathrm{~mm}$, HayeSep N packing material, 60/80 mesh size). Argon was used as a carrier gas at a flow rate of $30 \mathrm{~mL} \mathrm{~min}^{-1}$ under 46.2 psi. 
Electron Microscopy - Scanning electron microscopy (SEM) was carried out using a Nova NanoSEM electron microscope at an accelerating voltage of $5 \mathrm{kV}$ and a working distance of 5 $\mathrm{mm}$. Films were prepared on ITO as described above and fixed to an aluminum stub using carbon tape (SPI supplies). A secondary electron (SE) detector was used to obtain images of the fine nanostructured features of the nanoparticle electrodes and a back scattered electron (BSE) detector was used to visualize the Pt nanoparticle catalyst on the nanostructured electrodes. BSE images are contrasted by atomic number, where the bright phases correspond to the species with a higher atomic number. This is especially useful in this work as it allows to distinguish between nanoparticle catalysts from nanoparticle support. Bright field transmission electron microscopy (TEM) images were acquired with an FEI Tecnai Osiris scanning transmission electron microscope (FEI Company, Hillsboro, OR, USA) operated at $200 \mathrm{kV}$. TEM samples were prepared by dropping an IPA solution of the NP dispersion on a TEM grid having an ultrathin carbon film on a lacey carbon support (Prod \#01824, Ted Pella Inc).

Spectroscopy - UV Absorption spectra were recorded on a Cary 300 Bio UV-visible Spectrophotometer (Agilent Technologies). All solution samples were diluted to an appropriate concentration and measurements were performed in quartz cuvettes. All thin film samples were $\sim 90 \mathrm{~nm}$ thick and prepared on ITO-coated glass substrates. Absorption intensities of each spectra were normalized to their respective $\lambda_{\max }$ values. Steady-state fluorescence emission spectra were performed using a PTI Quantamaster spectrofluorometer with a xenon short arc lamp (Ushio Inc.) as the excitation source. All thin film samples were mounted $22.5^{\circ}$ normal to the incident light. All spectra were recorded using an excitation wavelength of $515 \mathrm{~nm}$, coinciding with their $\lambda_{\max }$ values as determined by UV-Vis. 
Grazing Incidence Small Angle X-ray Scattering - GIWAXS measurements were performed on a SAXSLAB Ganesha 300XL instrument using a photon wavelength of $1.54 \AA$. Measurements were taken under vacuum at an angle of incidence of $0.16^{\circ}$ and the scattered intensity was detected on a Pilatus3 R 300K detector. Data analysis was performed using the saxsgui version 2.15 .02 software package.

Dynamic Light Scattering - DLS measurements were performed using a Zetasizer Nano ZS (Malvern Instrument). 1 drop of the nanoparticle dispersion $(2.7 \mathrm{mg} / \mathrm{mL}$ ) was diluted in $2 \mathrm{~mL}$ of the appropriate solvent and measurements were performed in plastic cuvettes with a $1 \mathrm{~cm}$ path length.

\section{Results and Discussion}

\section{Nanoparticle Synthesis}

P3HT:PC ${ }_{61} B M$ NPs were synthesized via a surfactant-free precipitation method as described above. Various combinations of solvent (in which polymer:fullerene solutions were prepared) and non-solvent (in which the polymer:fullerene solutions were mixed) were investigated in order to study the synergistic effect on both the size of nanoparticles and nature of aggregation of the polymer chains (i.e., crystalline vs. amorphous). Solvents/non-solvents were chosen by considering the solubility data (reported by Machui et al.) ${ }^{36}$ of both P3HT and $\mathrm{PC}_{61} \mathrm{BM}$ (Table 1).

While poor solubility in the non-solvent ensures that the blend of $\mathrm{P} 3 \mathrm{HT}$ and $\mathrm{PC}_{61} \mathrm{BM}$ will co-precipitate upon the addition of the $\mathrm{P} 3 \mathrm{HT}: \mathrm{PC}_{61} \mathrm{BM}$ solution to the non-solvent, the physical 
properties of both the solvent and non-solvent are important to the formation of NP films.

Employing a solvent which possesses a lower boiling point and higher vapour pressure than the non-solvent ensures that the "good" solvent of the solution evaporates prior to evaporation of the non-solvent during the spin coating process. If the non-solvent evaporates prior to the evaporation of the good solvent, the nanoparticles are at risk of being re-dissolved by residual solvent during spin casting, which may result in $\mathrm{P} 3 \mathrm{HT}: \mathrm{PC}_{61} \mathrm{BM}$ more akin to those cast from homogenous solutions.

Table 1. Solubility of P3HT \& $P C_{61} B M$ in various solvents ${ }^{36}$ and solvent properties.

\begin{tabular}{lllll}
\hline & $\begin{array}{l}\text { P3HT solubility } \\
(\mathbf{m g} / \mathbf{m L})\end{array}$ & $\begin{array}{l}\mathbf{P C}_{61} \text { BM } \\
\text { solubility } \\
(\mathbf{m g} / \mathbf{m L})\end{array}$ & $\begin{array}{l}\text { Boiling Point } \\
\left({ }^{\circ} \mathbf{C}\right)\end{array}$ & $\begin{array}{l}\text { Vapor Pressure } \\
(\mathbf{m m H g})\end{array}$ \\
\hline $\begin{array}{l}\text { Solvents } \\
\text { o-dichlorobenzene } \\
\text { chloroform }\end{array}$ & 15 & 42 & 180 & 1.2 \\
tetrahydrofuran & 14 & 29 & 61 & 158 \\
& 1 & 2 & 65 & 145 \\
Non-solvents & & & & \\
1-butanol & $<0.1$ & $<0.1$ & 118 & 4.5 \\
2-propanol & $<0.1$ & $<0.1$ & 83 & 33 \\
methanol & $<0.1$ & $<0.1$ & 65 & 92 \\
ethanol & $<0.1$ & $<0.1$ & 78 & 43 \\
dimethylsulfoxide & $<0.1$ & $<1$ & 189 & 0.8 \\
water & $<0.1$ & $<0.1$ & 100 & 17
\end{tabular}

Based on the above criteria, of those listed only $\mathrm{CHCl}_{3}$ and $\mathrm{THF}$ were consider for further use, as $0-D C B$ is not removed prior to the non-solvent during the spin coating process due to its higher boiling point and lower vapor pressure. The physical properties of the non-solvent are equally as important to consider to insure good film formation during the spin coating process. Although many non-solvents meet the required criteria of low $\mathrm{P} 3 \mathrm{HT}$ and $\mathrm{PC}_{61} \mathrm{BM}$ solubility, high boiling point and low vapor pressure, those with very high boiling points and very low volatility 
are not completely removed during the spin casting process, leading to excessively long drying times. For this reason, DMSO, BuOH and water were rejected as non-solvents and not considered further.

In the surfactant-free precipitation method employed, the stability of the nanoparticles in the non-solvent is also important as there is no surfactant to mitigate potential electrostatic interactions between nanoparticle surfaces which could lead to aggregation. It was found that non-solvents possessing more amphiphilic character were able to act as both non-solvent and surfactant, leading to stable nanoparticle dispersions. This was apparent in the series of alcohols where nanoparticles prepared in $\mathrm{MeOH}$ aggregated within a few hours, whereas nanoparticles prepared in $\mathrm{BuOH}$ were stable over several days. As the alkane chain length of the alcohol is increased, the stability increases due to their increasing amphiphilic nature; however, boiling point and vapor pressure rapidly increase and decrease, respectively, with higher carbon homologues, rendering alcohols with aliphatic chains longer than propanol impractical for the formation of nanoparticle films.

\section{Characterization of Nanoparticles}

Dynamic light scattering (DLS) and transmission electron microscopy (TEM) were used to determine the size of nanoparticles formed. The DLS data shown in figure 3a implies that a distribution of nanoparticle sizes exists in solution with a z-average diameter of $140 \mathrm{~nm}$. TEM images in figure $3 \mathrm{~b}$ indicate smaller nanoparticle sizes than those obtained by DLS, but a distribution of sizes, nonetheless, with larger nanoparticles having diameters of $\sim 100 \mathrm{~nm}$ and smaller nanoparticles having diameters of $\sim 50 \mathrm{~nm}$. DLS measures the hydrodynamic radius, but 
the measurements rely upon Rayleigh scattering, where intensity of Rayleigh scattering scales with the $6^{\text {th }}$ power of particle diameter. Therefore the presence of larger aggregates skews the average size of the nanoparticles to larger than actual values. ${ }^{33}$

As shown in figure 4, UV-Vis absorption spectra of the nanoparticle dispersions exhibit an absorption maximum situated at $515 \mathrm{~nm}$, with a vibronic shoulder at $600 \mathrm{~nm}$. The red shift in the nanoparticle absorption spectra, with respect to the absorption of $\mathrm{P} 3 \mathrm{HT}$ dissolved in solution, as well as the existence of a vibronic shoulder are indicative of inter-chain interactions due to $\pi-\pi$ stacking. These features suggests that semi-crystalline domains of P3HT are formed during formation of nanoparticles. ${ }^{26}$ The absorption spectra of the nanoparticle dispersions possess similar absorption spectra to NP films prepared therefrom, in contrast to films cast from $\mathrm{P} 3 \mathrm{HT}$ polymer solutions where significant interchain interactions are absent in solution but evolve during film casting. Comparing the absorption spectra of nanoparticle and polymer solution-cast films, similar absorption maxima are observed, however, the solution-cast film exhibits a weaker vibronic shoulder intensity. Considering the $\mathrm{H}$-aggregate model, ${ }^{38,39}$ it may be concluded that the ratio of aggregated to non-aggregated polymer domains is larger for the nanoparticle film than solution-cast films. However, limitations on over-interpretating the relevance of the $\mathrm{H}$-aggregate model from UV-Vis spectroscopy have recently been raised. ${ }^{40}$ These limitations arise due to the sensitivity of UV-Vis spectra to reflections at polymer boundary layers and the influence of film thickness and refractive index on reflectance. The latter is especially relevant when comparing nanoparticle-cast and solution-cast films, as the surface morphologies are expected to differ significantly. 
Further information on the comparative aggregation within the nanoparticle and solution-cast films was obtained by grazing incidence wide-angle x-ray scattering (GIWAXS). GIWAXS plots are shown in figure 5 . The scattering peak situated at $q=0.4 \AA^{-1}$ (d-spacing of $15.7 \AA$ ) arises from the lamellar stacking of P3HT crystallites in the $a$-axis orientation, often referred to as the edge-on orientation, where the main chain is parallel and side chains extend perpendicularly to the plane of the substrate. This orientation is considered the (100) plane in P3HT films. The relative intensity of the scattering peak at $q=0.4 \AA^{-1}$ is proportional to the number of $\mathrm{P} 3 \mathrm{HT}$ nanodomains within the $\mathrm{P} 3 \mathrm{HT}: \mathrm{PC}_{61} \mathrm{BM}$ films, and therefore proportional to the semi-crystallinity of the samples. ${ }^{41}$ The similar relative scattering intensity of the nanoparticle and thin film samples suggests a similar extent of semi-crystallinity between the two. The 2D plot shown for the nanoparticle electrodes, figure $5 b$, shows polymer chains with nearly isotropic orientation as characterized by the broad ditribution of intensity for all peaks, whereas the 2D plot of the solution-cast elecrode, figure $5 c$, shows only the (100) peak along $q_{x}$ with a faint trace of the (200) peak, also along $\mathrm{q}_{\mathrm{x}}$.

Fluorescence spectroscopy was used to investigate charge separation within the photoelectrodes. Due to high excitonic binding energies of conjugated polymers, the exciton diffusion lengths are on the order of $\sim 10 \mathrm{~nm} .{ }^{42}$ To compensate for the short exciton diffusion lengths, electron acceptors, such as $\mathrm{PC}_{61} \mathrm{BM}$, have been introduced in order to promote efficient charge separation. If the exciton recombines prior to reaching the donor/acceptor interface, radiative emission may occur in the form of fluorescence. Ultafast photoinduced electron transfer from a conjugated polymer to fullerene in bulk heterojunction films was first reported by Sariciftci et al. ${ }^{43}$ and more recently Clafton et al. have shown that these same 
ultrafast electron transfer processes occur within P3HT:PCBM nanoparticle systems, confirming that P3HT:PCBM NPs exhibit similar exciton diffusion dynamics to solution-cast films. ${ }^{24}$ Photinduced electron transfer manifests itself in quenching of the photoluminescence intensity of the conjugated polymer film. Improving the bulk heterojunction, by increasing the interfacial surface area between the donor and acceptor phases, leads to enhanced quenching of the photoluminescence. Figure 6 shows the steady-state fluorescence spectra for both the NP and solution cast $\mathrm{P} 3 \mathrm{HT}: \mathrm{PC}_{61} \mathrm{BM}$ films, as well as a pristine $\mathrm{P} 3 \mathrm{HT}$ film for reference. A clear increase in quenching of the fluorescence is observed for both the NP and solution-cast films due to the presence of $\mathrm{PC}_{61} \mathrm{BM}$. A possible advantage which semiconducting NPs offer is greater control of the nanoscale morphology by controlling the extent of phase segregation within each nanoparticle rather than over the entire active layer. ${ }^{30}$ The enhanced quenching observed for the P3HT:PC ${ }_{61} B M$ NP films, with respect to the solution-cast film may be due to enhanced control of the donor/acceptor phase segregation on the nanoscale.

SEM images of the P3HT:PC ${ }_{61} \mathrm{BM}$ nanoparticles cast on ITO electrodes are shown in figure 7, from which the diameter of the nanoparticles is estimated to be between 50 and 100 $\mathrm{nm}$, coinciding with the TEM results described above. Under lower magnification, figure 7a, a homogeneous distribution of $\mathrm{P} 3 \mathrm{HT}: \mathrm{PC}_{61} \mathrm{BM}$ nanoparticles is observed across the electrode, free from the formation of large aggregates. Under higher magnifications, figure $7 \mathrm{~b}$, layers of partially coalesced spherical NPs are observed, confirming the formation of nanostructured electrodes. Partial coalescence may be caused by trace $\mathrm{CHCl}_{3}$ remaining in the nanoparticle dispersion. Although the $\mathrm{CHCl}_{3}$ solvent evaporates prior to the alcohol during the spin casting process, its presence during each subsequent coating may be sufficient to promote 
plasticization and partial coalescence of the nanoparticles. Partial coalescence of NPs may, in fact, be beneficial to photocathode activity, as previous reports have shown that coalescence of P3HT:ICBA (indene- $\mathrm{C}_{60}$ bisadduct) nanoparticles, by thermal annealing, increases the performance of organic photovoltaic devices due to the increase in the short-circuit current density brought about by the connectivity of nanoparticles. ${ }^{37}$

\section{Photoelectrochemistry of Nanoparticle-based Photocathodes}

Photocathodes were prepared by depositing both $\mathrm{P} 3 \mathrm{HT}: \mathrm{PC}_{61} \mathrm{BM}$ NPs and solution-cast P3HT:PC ${ }_{61} B M$ films onto ITO, followed by the photoelectrochemical deposition of platinum nanoparticles by potentiostatic coulometry, figure 8 . By taking advantage of the photoreductive activity of $\mathrm{P} 3 \mathrm{HT}$ and the position of the redox potential associated with the $\mathrm{PtCl}_{6}{ }^{2-}$ anion at 0.49 $V$ (vs. SCE), which is positive of both $\mathrm{P} 3 \mathrm{HT}$ and $\mathrm{PC}_{61} \mathrm{BM}$ LUMO energy levels, it is possible to reduce $\mathrm{PtCl}_{6}{ }^{2-}$ to metallic $\mathrm{Pt}$ on the electrode surface by irradiation of the $\mathrm{P} 3 \mathrm{HT}: \mathrm{PC}_{61} \mathrm{BM}$ photocathode under a negative bias (-100 mV vs. SCE). The photocurrents observed are attributed to the reduction of $\mathrm{PtCl}_{6}{ }^{2-}$ to $\mathrm{Pt}^{0}$. SEM images of the electrodes obtained using a back scattered electron detector illustrate that Pt nanoparticle catalysts (bright spots) are deposited in uniform size and distribution on the $\mathrm{P} 3 \mathrm{HT}: \mathrm{PC}_{61} \mathrm{BM}$ NP and solution-cast films, figure 9.

Linear sweep voltammetry of the photoelectrodes in aqueous solution, figure 10a, confirm the role of Pt catalyst on the nature of the electrochemical reactions under irradiation as there is no appreciable photocurrent generated in their absence. After deposition of Pt electrocatalysts, however, a cathodic current is observed having an onset potential at $\sim 0.0 \mathrm{~V}$ (SCE), which is slightly more negative than the reported flat-band potential of P3HT $0.1 \mathrm{~V}$ (SCE) in similar solutions. ${ }^{44}$ It is not uncommon for the onset potential to appear up to a few hundred 
millivolts more negative than the flat-band potential due to recombination in the space charge layer near flat band potential, charge trapping at surface defects and/or poor charge transfer kinetics which leads to charge accumulation at the surface. ${ }^{45}$ Negligible dark currents are observed for both the $\mathrm{P} 3 \mathrm{HT}: \mathrm{PC}_{61} \mathrm{BM}$ nanoparticle and $\mathrm{P} 3 \mathrm{HT}: \mathrm{PC}_{61} \mathrm{BM}$ solution-cast photocathodes, however, the nanoparticle photoelectrodes exhibit a small dark current at potentials more negative than $-0.3 \mathrm{~V}(\mathrm{SCE})$ which may be due to electrocatlytic evolution of $\mathrm{H}_{2}$ at Pt which has been inadvertently deposited onto exposed ITO sites during the Pt deposition process. Voltammograms of Pt deposited on blank ITO were recorded, figure 10c, and show the onset of $\mathrm{H}_{2}$ at the ITO/Pt electrodes correlates well with the onset of dark current at the ITO/Pt electrodes.

In order to minimize the influence of $\mathrm{H}_{2}$ directly evolved at ITO/Pt sites during the photo-assisted hydrogen evolution experiments, all subsequent photo-electrolysis experiments were performed at sufficiently positive potentials (-240 mV vs. SCE) where the dark current was negligible. Potentiostatic coulometry data of the $\mathrm{P} 3 \mathrm{HT}: \mathrm{PC}_{61} \mathrm{BM}$ nanoparticle and of the solutioncast films, both with and without Pt catalyst, are presented in figure 10b. The experiments were performed under chopped illumination, where significant currents are only observed during the illumination of the photoelectrodes and return to negligible current in the dark, confirming that photogenerated charges within the polymer films are responsible for the redox reactions which occur at the interfaces of the working and counter electrodes within the photoelectrochemical cell.

Photocurrents obtained during electrolysis are increased from sub- $\mu \mathrm{A}$ values at uncatalyzed photoelectrodes to $35 \mu \mathrm{A} / \mathrm{cm}^{2}$ and $7 \mu \mathrm{A} / \mathrm{cm}^{2}$ for the Pt-deposited, $\mathrm{P} 3 \mathrm{HT}: \mathrm{PC}_{61} \mathrm{BM}$ 
nanoparticle and the Pt-deposited solution-cast photoelectrodes, respectively. To confirm hydrogen evolution at the nanoparticle photocathodes, electrolysis was performed for 1 hour and the headspace was positively identified by gas chromatography as containing hydrogen.

Although larger photocurrents are observed at the nanoparticle photoelectrodes compared to their solution-cast film counterparts, it is noted that the increased surface area of the nanoparticle electrodes facilitates a larger quantity of Pt electrocatalyst to be deposited when subjected to identical Pt deposition times under identical conditions. The mass of Pt deposited was calculated using the total charge passed during photoelectrochemical deposition, the details of which are provided in the experimental details, which is a reasonable assumption as the solution had been thoroughly purged with $\mathrm{N}_{2}$ to remove any dissolved oxygen. For the voltammetric and coulometric curves provided, the loading of Pt catalyst deposited on the nanoparticle and solution-cast electrodes films were 1.11 and $0.21 \mu \mathrm{g} / \mathrm{cm}^{2}$ respectively.

Studies of Pt-loading were performed using the solution-cast polymer film electrodes in order to determine the effect of increasing the Pt deposition period. Figure 11 shows LSV and electrolysis curves of solution-cast electrodes for which Pt has been deposited for periods of 100, 250 and 500 seconds. These results show that it is detrimental to extend Pt deposition for long periods of time. As deposition time is extended, the size of the catalyst particles increases ${ }^{46}$, resulting in a decreased catalytic surface area and thus decreased catalytic activity. ${ }^{47}$ The dark current observed for electrodes after a deposition period of $500 \mathrm{~s}$ is presumably due to the Pt catalyst particles growing large enough to create a short circuit with the underlying ITO substrate. Although the Pt loading at solution-cast electrodes can be 
increased to match that of the NP electrodes, doing so reduces the catalytic surface area, leading to a decrease in performance.

\section{Conclusion}

We have investigated the fabrication of $\mathrm{P} 3 \mathrm{HT}: \mathrm{PC}_{61} \mathrm{BM}$ nanoparticle photocathodes and compared their performance with solution-cast $\mathrm{P} 3 \mathrm{HT}: \mathrm{PC}{ }_{61} \mathrm{BM}$ photocathodes. The nanoparticle and solution-cast electrodes show similar optoelectronic properties as shown by UV-Vis and fluorescence spectroscopy, as well as similar crystallinities as determined by GISAXS. The larger surface area of the nanoparticle electrodes allows for greater amounts of platinum to be deposited during the catalyst deposition process, consequently leading to enhanced photoelectrochemical performance. Pt-loading studies at solution-cast electrodes show that increasing the Pt deposition period past a certain point will begin to have adverse effects on photoelectrochemical performance, as catalyst particles grow larger with increasing deposition time, thus decreasing catalytic surface area.

For photoelectrochemical reactions plagued by slow electron transfer kinetics at the polymer/electrolyte interface, such as the HER, the performance of the electrodes will be determined by catalyst loading, as the catalyst is the only site at which reduction occurs. There are, however, photoelectrochemical reactions which have been shown to occur directly at the polymer/electrolyte interface in the absence of an electrocatalyst, such as the reduction of $\mathrm{O}_{2}{ }^{48}$ and organic redox couples, such as anthraquinone-2,7-disulfonate (AQDS). ${ }^{49}$ The reduction of $\mathrm{O}_{2}$ and AQDS are of interest in the application of dissolved oxygen sensors and redox flow batteries, respectively. Further study of the photoelectrochemical reduction of various redox 
couples and employing different conjugated polymer nanoparticle-based photoelectrodes is underway.

\section{Acknowledgements}

This research was supported financially by the Natural Sciences and Engineering Research Council of Canada. The authors would like to thank the machine shop, electronic shop and glass blower (Bruce Harwood) at SFU for their assistance in manufacturing the PEC cell.

\section{Corresponding Author}

E-mail: holdcrof@sfu.ca (S. Holdcroft)

\section{Author Contributions}

The manuscript was written through contributions of all authors. All authors have given approval to the final version of the manuscript.

\section{References}

(1) Chen, J.; Cui, C.; Li, Y.; Zhou, L.; Ou, Q. Adv. Funct. Mater. 2014, 27, 1035.

(2) He, Z.; Xiao, B.; Liu, F.; Wu, H.; Yang, Y.; Xiao, S.; Wang, C.; Russell, T. P.; Cao, Y. Nat. Photonics 2015, 9, 174.

(3) Liu, Y.; Zhao, J.; Li, Z.; Mu, C.; Ma, W.; Hu, H.; Jiang, K.; Lin, H. Nat. Commun. 2014, 5, 5293.

(4) Zhao, J.; Li, Y.; Yang, G.; Jiang, K.; Lin, H.; Ade, H.; Ma, W.; Yan, H. Nat. Energy 2016, 1, 15027.

(5) Heliatek. Heliatek sets new Organic Photovoltaic world record efficiency of 13.2\%; 2016. 
(6) Walter, M. G.; Warren, E. L.; Mckone, J. R.; Boettcher, S. W.; Mi, Q.; Santori, E. A.; Lewis, N. S. Chem. Rev. 2010, 110, 6446.

(7) Osterloh, F. E. Chem. Soc. Rev. 2013, 42, 2294.

(8) Hisatomi, T.; Kubota, J.; Domen, K. Chem. Soc. Rev. 2014, 43, 7520.

(9) Vesborg, P. C. K.; Seger, B.; Chorkendor, I. J. Phys. Chem. Lett. 2015, 6, 951.

(10) El-Rashiedy, O. A.; Holdcroft, S. J. Phys. Chem. 1996, 100, 5481.

(11) Lanzarini, E.; Antognazza, M. R.; Biso, M.; Ansaldo, A.; Laudato, L.; Bruno, P.; Metrangolo, P.; Resnati, G.; Ricci, D.; Lanzani, G. J. Phys. Chem. C 2012, 116, 10944.

(12) Gustafson, M. P.; Clark, N.; Winther-Jensen, B.; MacFarlane, D. R. Electrochim. Acta 2014, $140,309$.

(13) Suppes, G. M.; Fortin, P. J.; Holdcroft, S. J. Electrochem. Soc. 2015, 162, H551.

(14) Bourgeteau, T.; Tondelier, D.; Geffroy, B.; Brisse, R.; Laberty-Robert, C.; Campidelli, S.; de Bettignies, R.; Artero, V.; Palacin, S.; Jousselme, B. Energy Environ. Sci. 2013, 6, 2706.

(15) Belarb, E.; Blas-ferrando, V. M.; Haro, M.; Maghraoui-meherzi, H. Chem. Eng. Sci. 2016, $154,143$.

(16) Bourgeteau, T.; Tondelier, D.; Geffroy, B.; Brisse, R.; Cornut, R.; Artero, V.; Jousselme, B. ACS Appl. Mater. Interfaces 2015, 7, 16395.

(17) Haro, M.; Solis, C.; Molina, G.; Otero, L. A.; Bisquert, J.; Gimenez, S.; Guerrero, A. J. Phys. Chem. C 2015, 119, 6488.

(18) Rojas, H. C.; Marra, G.; Meda, L.; Lanzani, G.; Mayer, M. T.; Antognazza, M. R.; Fonzo, F. Di. J. Mater. Chem. A 2016, 4, 2178.

(19) Rojas, H. C.; Bellani, S.; Fumagalli, F.; Tullii, G.; Leonardi, S.; Mayer, M. T.; Schreier, M.; Gra, M.; Lanzani, G.; Fonzo, F. Di; Antognazza, M. R. Energy Environ. Sci. 2016, 9, 3710.

(20) Bourgeteau, T.; Tondelier, D.-; Geffroy, B.; Brisse, R.; Campidelli, S.; Cornut, R.; Jousselme, B. J. Mater. Chem. A 2016, 4, 4831.

(21) Foley, J. M.; Price, M. J.; Feldblyum, J. I.; Maldonado, S. Energy Environ. Sci. 2012, 5, 5203.

(22) Jung, J.-Y.; Park, M.-J.; Li, X.; Kim, J.-H.; Wehrspohn, R. B.; Lee, J.-H. J. Mater. Chem. A 2015, 3, 9456.

(23) Chen, F.; Zhu, Q.; Wang, Y.; Cui, W.; Su, X.; Li, Y. ACS 2016, 8, 31025.

(24) Clafton, S. N.; Huang, D. M.; Massey, W. R.; Kee, T. W. J. Phys. Chem. B 2013, 117, 4626.

(25) Holmes, N. P.; Burke, K. B.; Sista, P.; Barr, M.; Magurudeniya, H. D.; Stefan, M. C.; Kilcoyne, a. L. D.; Zhou, X.; Dastoor, P. C.; Belcher, W. J. Sol. Energy Mater. Sol. Cells 
2013, 117, 437.

(26) Labastide, J. A.; Baghgar, M.; Dujovne, I.; Venkatraman, B. H.; Ramsdell, D. C.;

Venkataraman, D.; Barnes, M. D. J. Phys. Chem. Lett. 2011, 2, 2089.

(27) Pedersen, E. B. L.; Pedersen, M. C.; Simonsen, S. B.; Brandt, R. G.; Böttiger, a. P. L.; Andersen, T. R.; Jiang, W.; Xie, Z. Y.; Krebs, F. C.; Arleth, L.; Andreasen, J. W. J. Mater. Chem. A 2015, 3, 17022.

(28) Nagarjuna, G.; Baghgar, M.; Labastide, J. A.; Algaier, D. D.; Barnes, M. D.; Venkataraman, D.; Amherst, M.; Street, N. P.; States, U. ACS Nano 2012, 12, 10750.

(29) Roy, P.; Jha, A.; Dasgupta, J. Nanoscale 2016, 8, 2768.

(30) Ulum, S.; Holmes, N.; Darwis, D.; Burke, K.; David Kilcoyne, a. L.; Zhou, X.; Belcher, W.; Dastoor, P. Sol. Energy Mater. Sol. Cells 2013, 110, 43.

(31) Darwis, D.; Holmes, N.; Elkington, D.; Kilcoyne, A. L. D.; Bryant, G.; Zhou, X.; Dastoor, P.; Belcher, W. Sol. Energy Mater. Sol. Cells 2014, 121, 99.

(32) Gärtner, S.; Christmann, M.; Sankaran, S.; Röhm, H.; Prinz, E.; Penth, F.; Pütz, A.; Türeli, A. E.; Penth, B.; Baumstümmler, B.; Colsmann, A. Adv. Funct. Mater. 2014, 26, 6653.

(33) Millstone, J. E.; Kavulak, D. F. J.; Woo, C. H.; Holcombe, T. W.; Westling, E. J.; Briseno, A. L.; Toney, M. F.; Fréchet, J. M. J. Langmuir 2010, 26, 13056.

(34) Darwis, D.; Holmes, N.; Elkington, D.; David Kilcoyne, a. L.; Bryant, G.; Zhou, X.; Dastoor, P.; Belcher, W. Sol. Energy Mater. Sol. Cells 2014, 121, 99.

(35) Schwarz, K. N.; Farley, S. B.; Smith, T. A.; Ghiggino, K. P. Nanoscale 2015, 7, 19899.

(36) Machui, F.; Langner, S.; Zhu, X.; Abbott, S.; Brabec, C. J. Sol. Energy Mater. Sol. Cells 2012, $100,138$.

(37) Gärtner, S.; Christmann, M.; Sankaran, S.; Röhm, H.; Prinz, E.-M.; Penth, F.; Pütz, A.; Türeli, A. E.; Penth, B.; Baumstümmler, B.; Colsmann, A. Adv. Mater. 2014, 26, 6653.

(38) Spano, F. C.; Silva, C. Annu. Rev. Phys. Chem. 2014, 65, 477.

(39) Spano, F. C. Acc. Chem. Res. 2010, 43, 429.

(40) Ehrenreich, P.; Birk, S. T.; Zimmermann, E.; Hu, H.; Kim, K.; Weickert, J.; Pfadle, T.; Schmidt-mende, L. Sci. Rep. 2016, 6, 32434.

(41) Erb, B. T.; Zhokhavets, U.; Gobsch, G.; Raleva, S.; Stühn, B.; Schilinsky, P.; Waldauf, C.; Brabec, C. J. Adv. Funct. Mater. 2005, 15, 1193.

(42) Lunt, R. R.; Giebink, N. C.; Belak, A. A.; Benziger, J. B.; Forrest, S. R.; Lunt, R. R.; Giebink, N. C.; Belak, A. A.; Benziger, J. B.; Forrest, S. R. J. Appl. Phys. 2009, 105, 53711.

(43) Sariciftci, N. S.; Smilowitz, L.; Heeger, a. J.; Wudl, F. Science (80-. ). 1992, 258, 1474. 
(44) Suppes, G.; Ballard, E.; Holdcroft, S. Polym. Chem. 2013, 4, 5345.

(45) van de Krol, R.; Grätzel, M. In Photoelectrochemical Hydrogen Evolution; Springer, 2012; pp. 13-67.

(46) Brülle, T.; Denisenko, A.; Sternschulte, H.; Stimming, U. Phys. Chem. Chem. Phys. 2011, 13, 12883.

(47) Lin, Z.; Ji, L.; Zhang, X. Mater. Lett. 2009, 63, 2115.

(48) Bellani, S.; Ghadirzadeh, A.; Meda, L.; Savoini, A.; Tacca, A.; Marra, G.; Meira, R.; Morgado, J.; Fonzo, F. Di; Antognazza, M. R. Adv. Funct. Mater. 2015, 25, 4531.

(49) Chowdhury, P.; Fortin, P.; Suppes, G.; Holdcroft, S. Macromol. Chem. Phys. 2016, 217, 1119. 


\section{Figures}

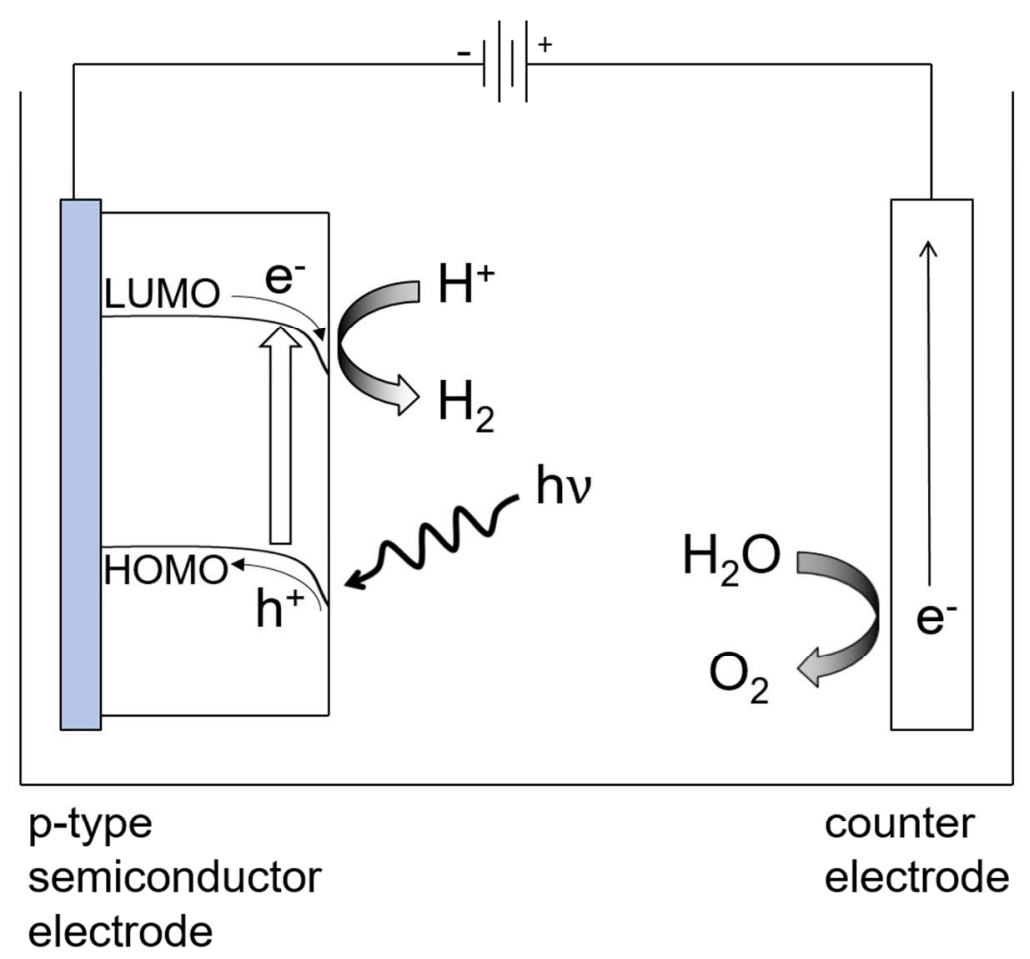

Figure 1. Diagram of an organic photoelectrochemical cell with a p-type organic semiconductor working electrode and counter electrode. 
a)
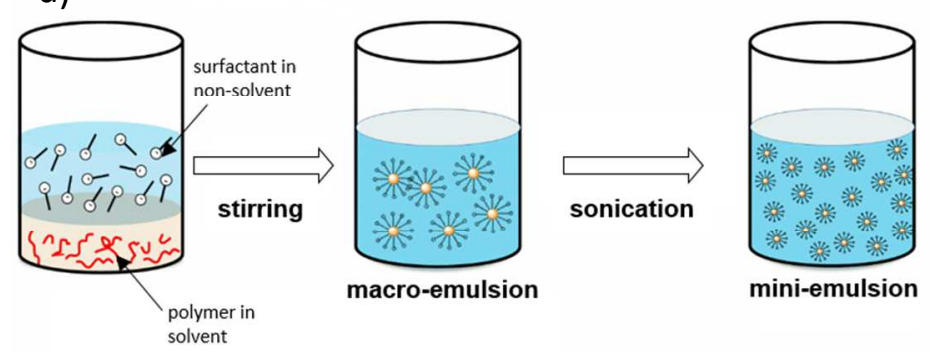

b)
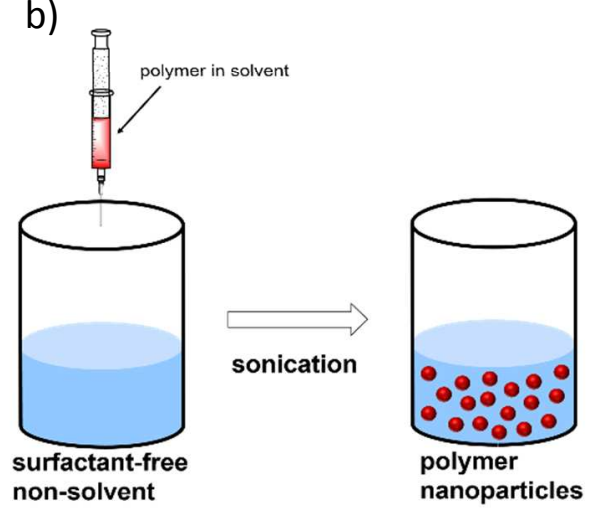

Figure 2. General schemes showing the formation of organic polymer nanoparticles by (a) the miniemulsion method and (b) the precipitation method. 
a)

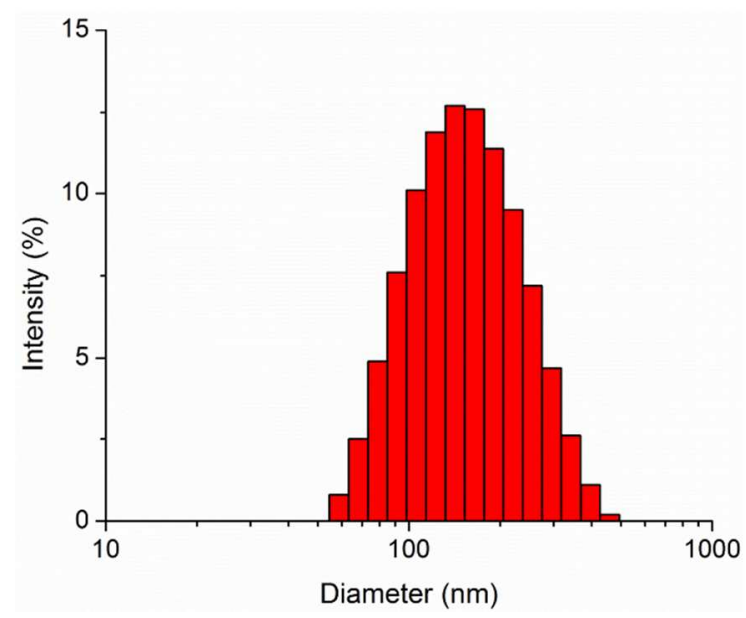

b)

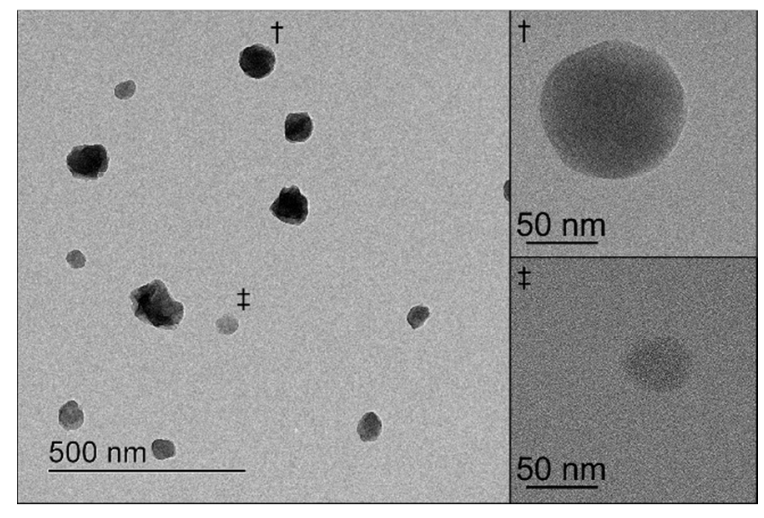

Figure 3. Size distribution of $\mathrm{P} 3 \mathrm{HT}: \mathrm{PC}_{61} \mathrm{BM}$ NP diameter determined by dynamic light scattering (DLS) (a) and transmission electron spectroscopy (TEM) images of P3HT:PC ${ }_{61} B M$ NPs (b). For DLS measurements, 1 drop of NP dispersion was diluted in 2 ml of IPA. TEM samples were prepared by drop casting a diluted NP dispersion in IPA on a lacey carbon TEM grid. 


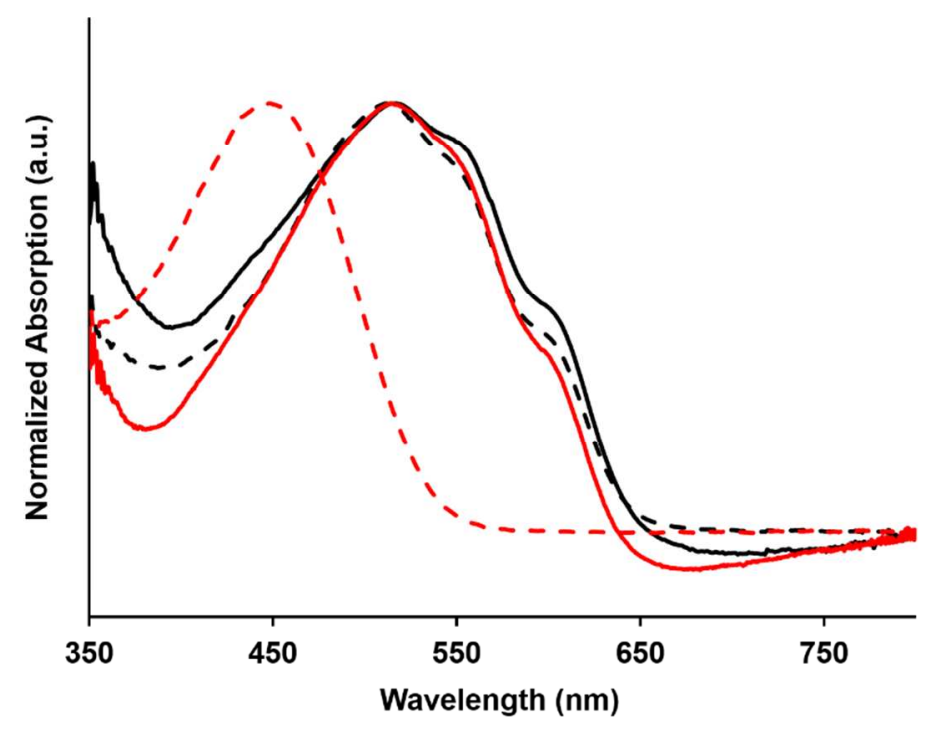

Figure 4. Normalized UV-Vis spectra of a P3HT:PC ${ }_{61} B M$ NP film (solid black), a solution cast P3HT:PC ${ }_{61} B M$ bulk heterjunction film (solid red), a dispersion of P3HT:PC ${ }_{61} B M$ NPs in IPA (dashed black) and a P3HT:PC ${ }_{61} \mathrm{BM}$ solution in o-DCB (dashed red). NP and solution cast films were $\sim 90 \mathrm{~nm}$ thick. 

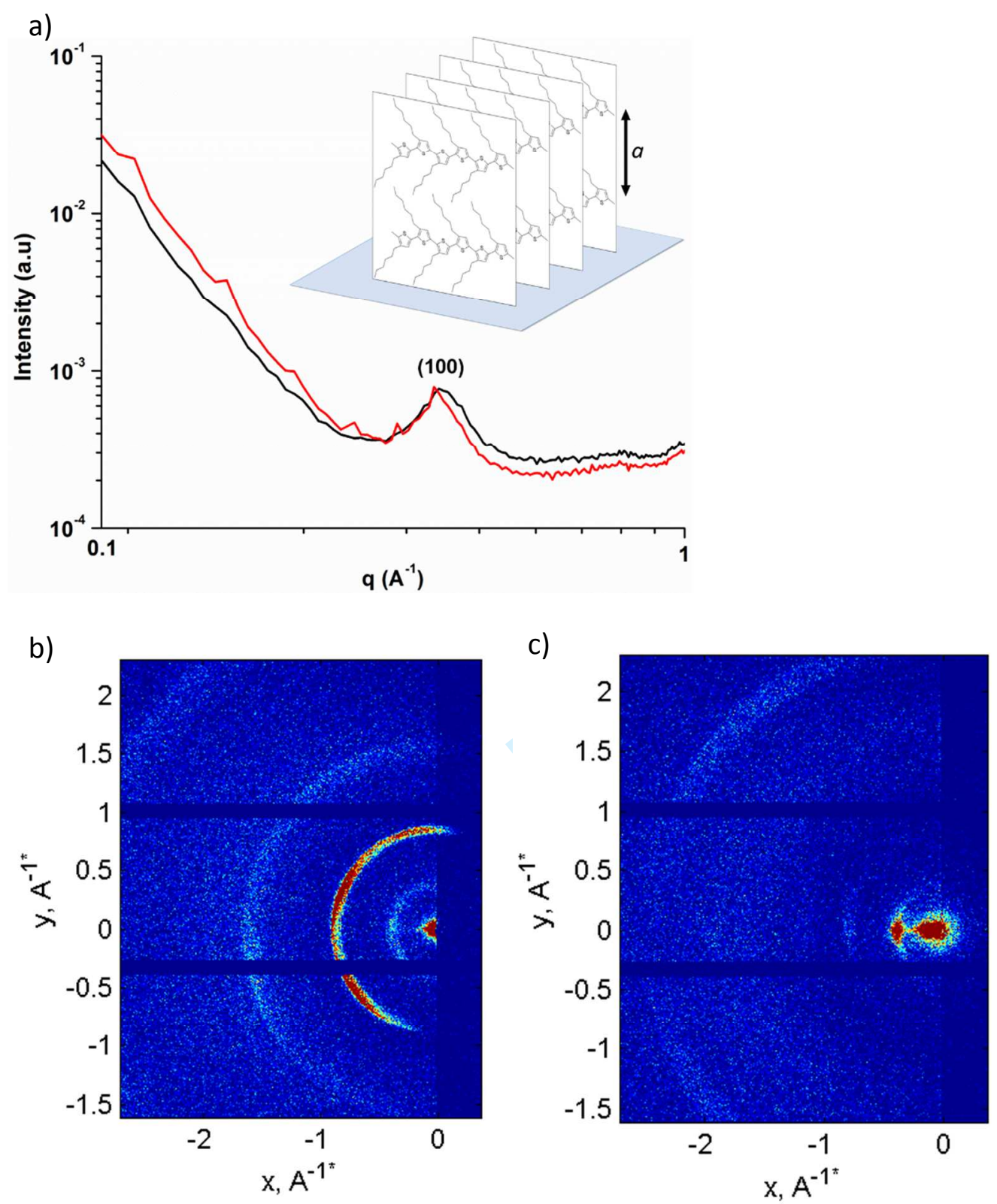

Figure 5. (a) Grazing incidence wide angle x-ray scattering (GIWAXS) data obtained for P3HT:PC ${ }_{61} B M$ nanoparticle (black) and solution-cast (red) films. The angle of incidence was $0.16^{\circ}$. Inset: Lamellar stacking of $\mathrm{P} 3 \mathrm{HT}$ chains in an edge-on fashion along the $a$-axis aka the (100) direction. 2D GIWAXS plots of the $\mathrm{P} 3 \mathrm{HT}: \mathrm{PC}_{61} \mathrm{BM}$ nanoparticle and solution-cast electrodes are shown in (b) and (c), respectively. 


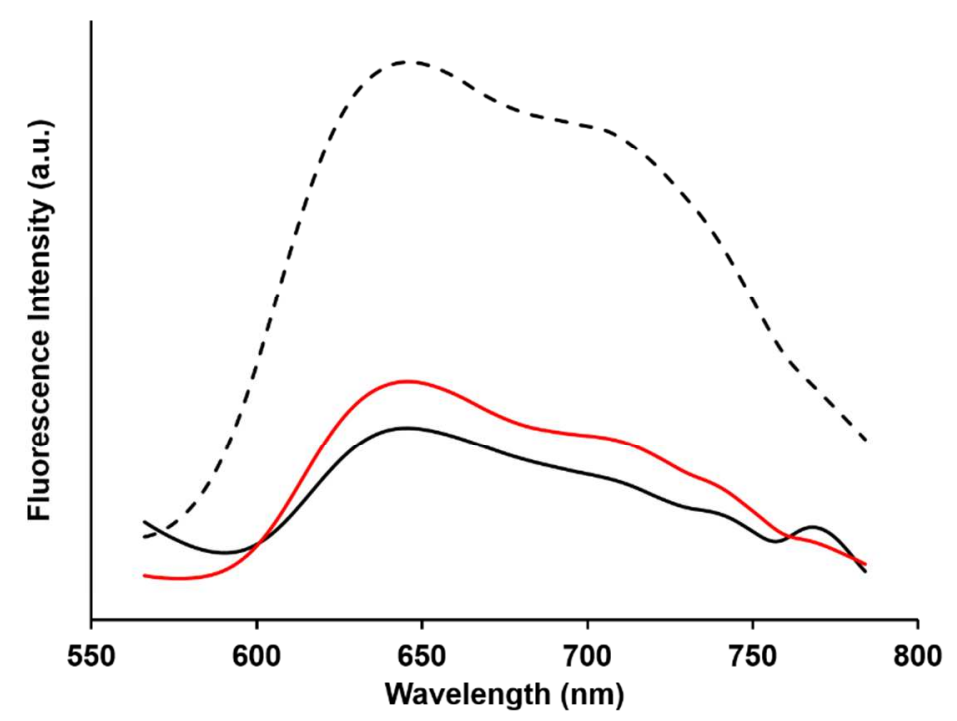

Figure 6. Steady-state fluorescence emission spectra of a solution-cast P3HT film (dashed), a solution cast P3HT:PC ${ }_{61} \mathrm{BM}$ film (red) and a $\mathrm{P} 3 \mathrm{HT}: \mathrm{PC}_{61} \mathrm{BM} N \mathrm{NP}$ (black) film, all on ITO. An excitation wavelength of $515 \mathrm{~nm}$ was used. 

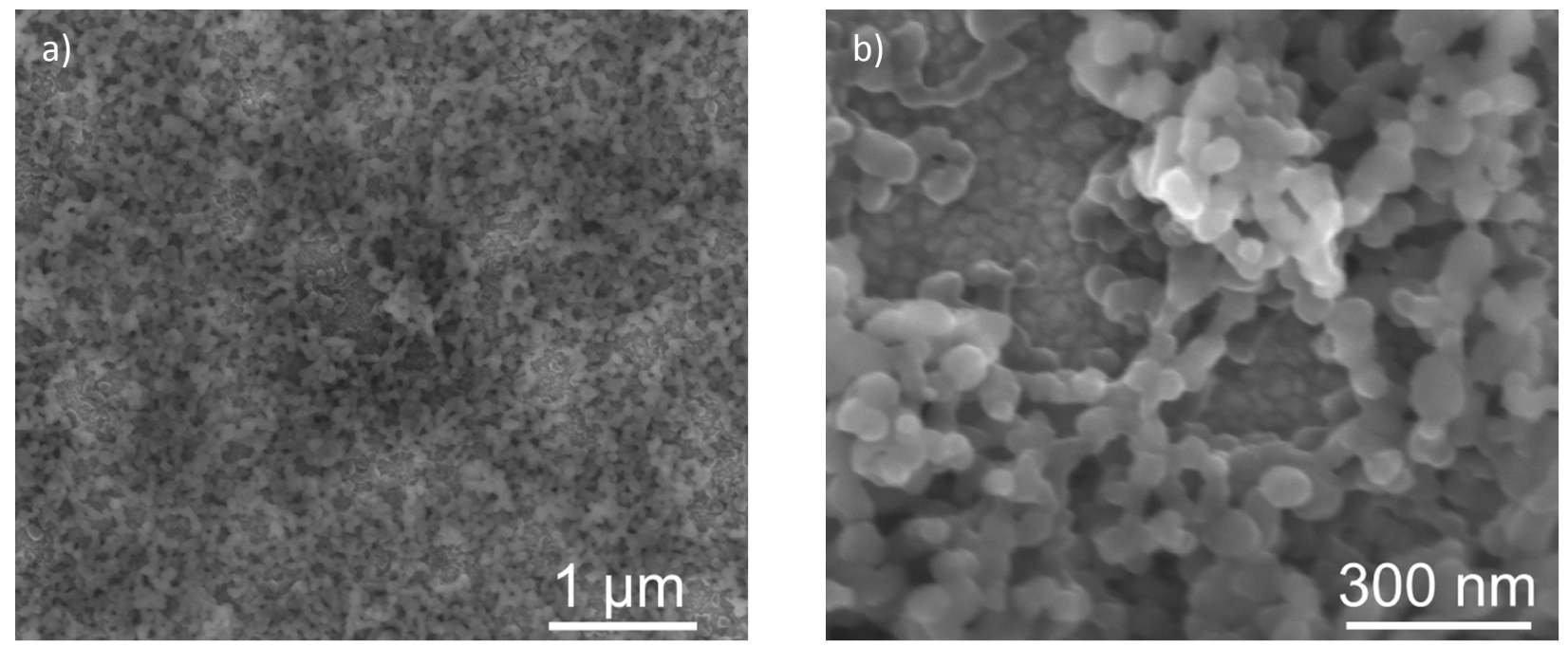

Figure 7. SEM images of a P3HT:PC ${ }_{61} \mathrm{BM}$ nanoparticles on ITO electrodes. Images (a) and (b) depict the nanoparticle films at magnification values of $60 \mathrm{k}$ and $250 \mathrm{k}$, respectively. 


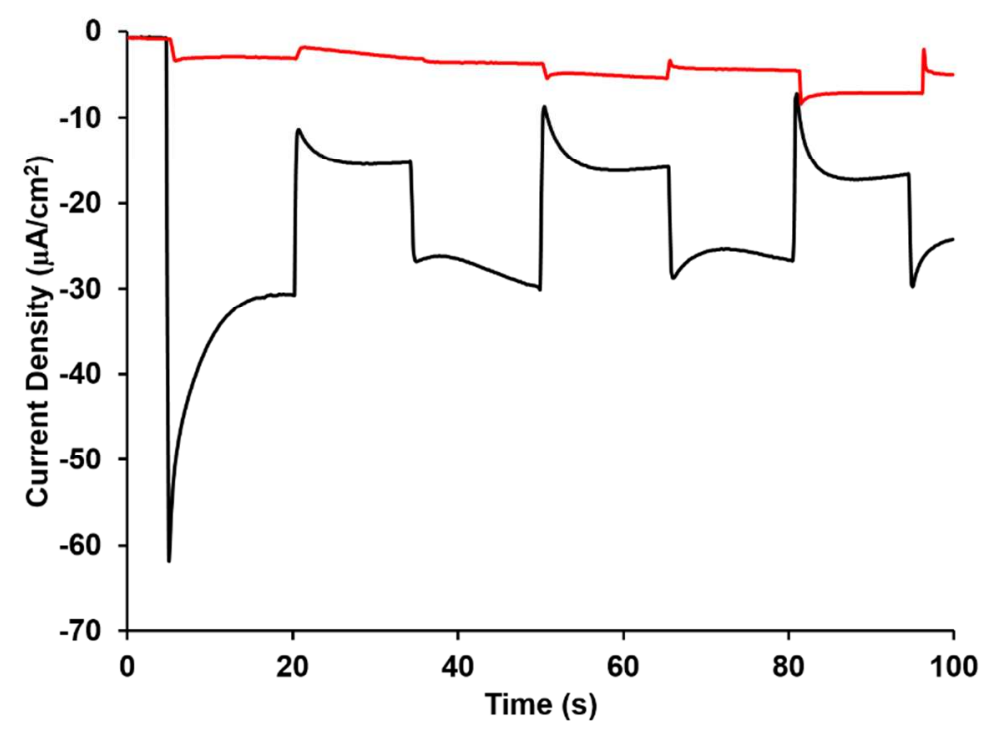

Figure 8. Platinum deposition by electrolysis under chopped illumination for $\mathrm{P} 3 \mathrm{HT}: \mathrm{PC}_{61} \mathrm{BM}$ nanoparticle (black) and solition-cast (red) films. The potential of the photoelectrodes was held at $-240 \mathrm{mV}$ (SCE). 

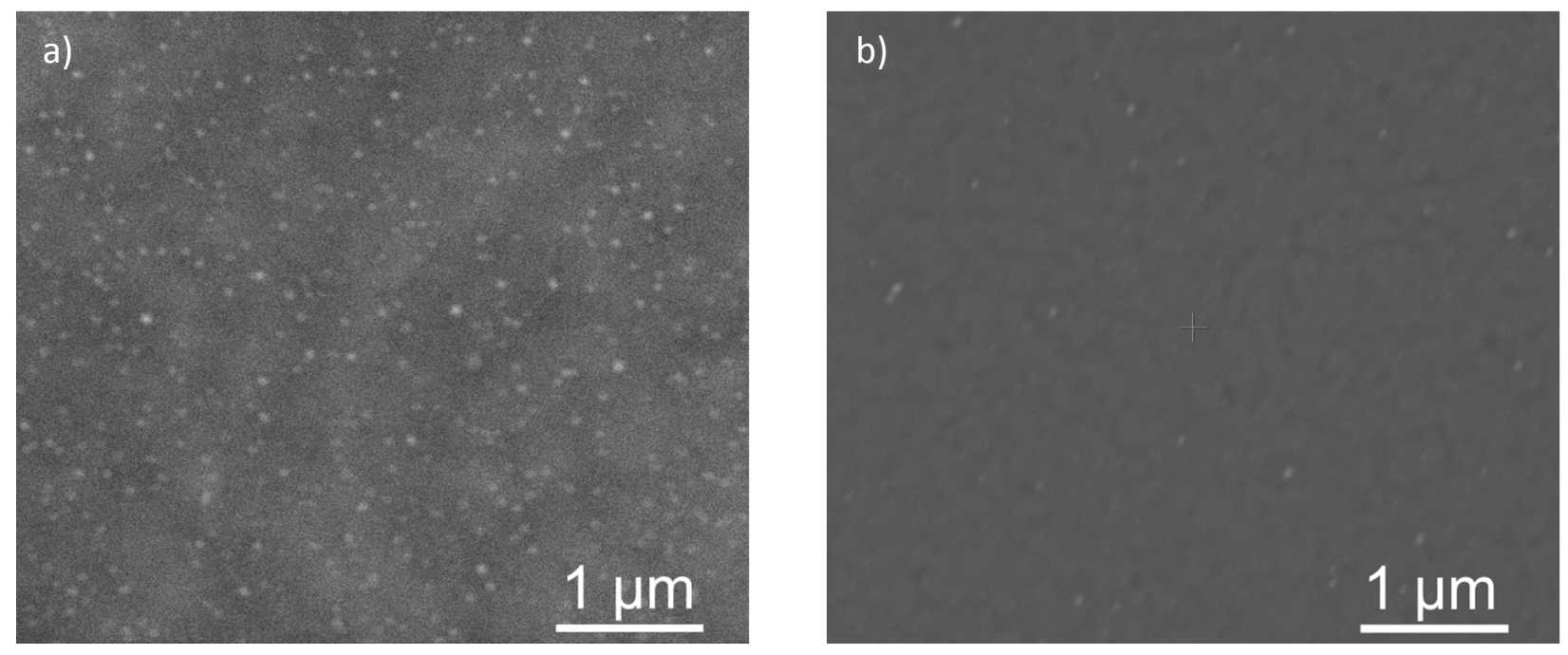

Figure 9. SEM images collected using the backscattered electron detector of Pt deposited after a deposition period of $100 \mathrm{~s}$ on $\mathrm{P} 3 \mathrm{HT}: \mathrm{PC}_{61} \mathrm{BM}$ nanoparticle electrode $(\mathrm{a})$ and on a solution-cast $\mathrm{P} 3 \mathrm{HT}: \mathrm{PC}_{61} \mathrm{BM}$ thin film electrode (b). 
a)

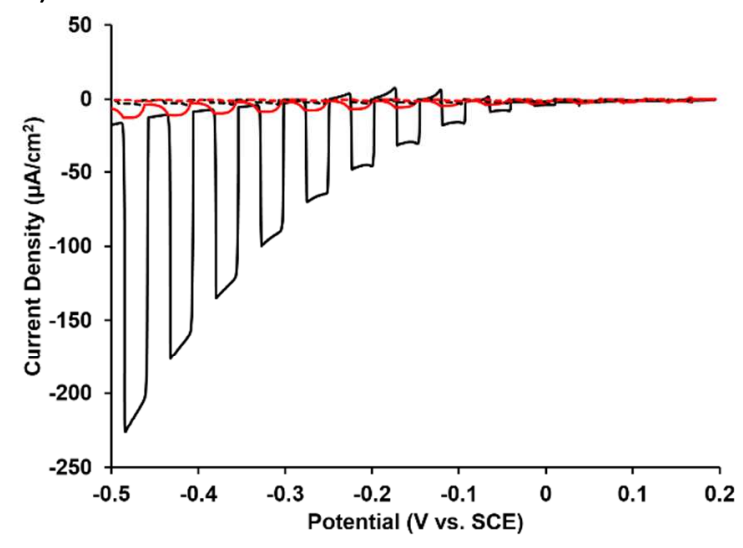

c)

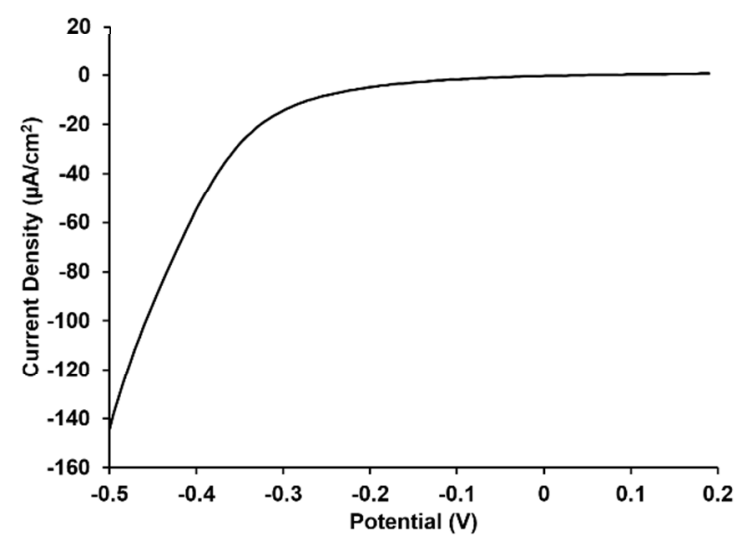

b)

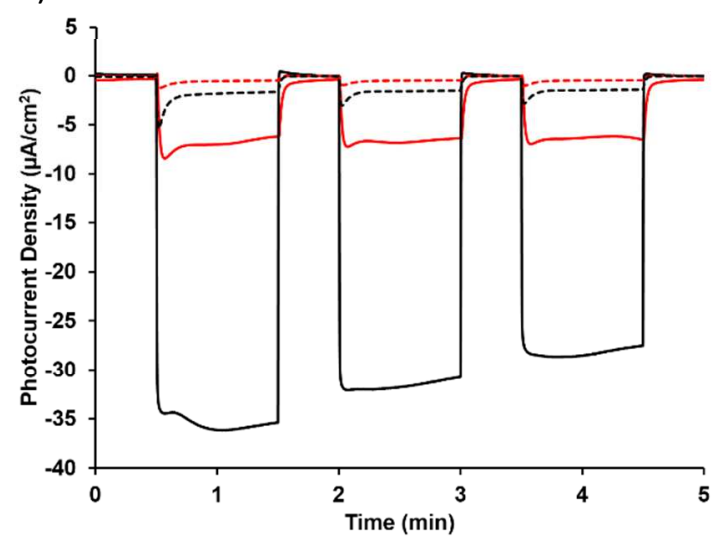

Figure 10. Linear sweep voltammetry (a) and electrolysis (b) under chopped illumination comparing $\mathrm{P} 3 \mathrm{HT}: \mathrm{PC}_{61} \mathrm{BM}$ nanoparticle (black) and solution-cast (red) photocathodes in $0.1 \mathrm{M} \mathrm{H}_{2} \mathrm{SO}_{4}$. Experiments were performed both with (solid) and without (dashed) Pt nanoparticle catalysts. Linear sweep voltammetry of Pt deposited on bare ITO is shown in (c). Linear sweep voltammograms were measured at a scan rate of $5 \mathrm{mVs}^{-1}$ and electrolysis measurements were performed at $-0.24 \mathrm{~V}$ (SCE). 
a)

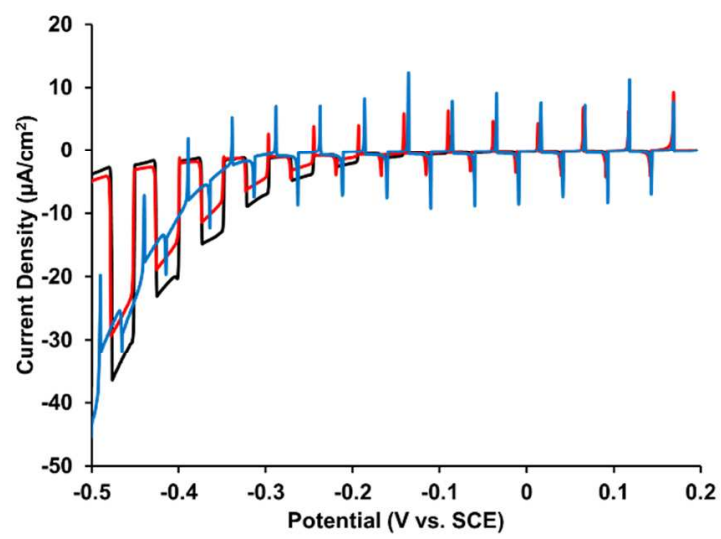

b)

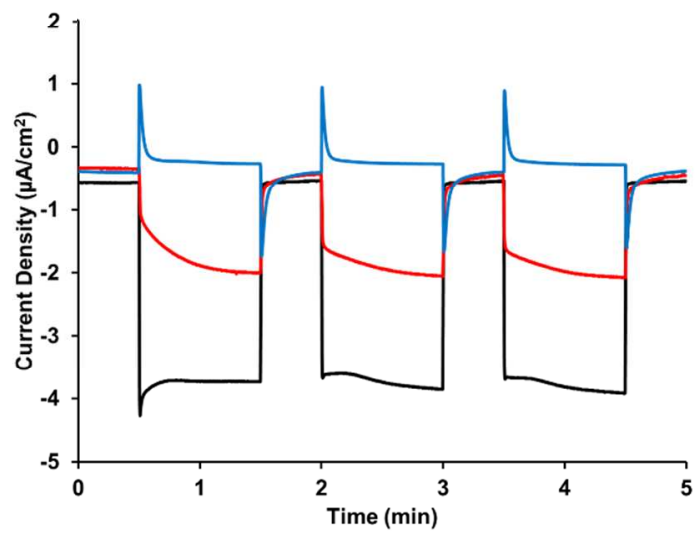

Figure 11. Linear sweep voltammetry (a) and electrolysis (b) under chopped illumination comparing $\mathrm{P} 3 \mathrm{HT}: \mathrm{PC}_{61} \mathrm{BM}_{\mathrm{S}}$ solution-cast photocathodes prepared using Pt deposition periods of $100 \mathrm{~s}$ (black), $250 \mathrm{~s}$ (red) and $500 \mathrm{~s}$ (blue). ). Linear sweep voltammograms were measured at a scan rate of $5 \mathrm{mVs}^{-1}$ and electrolysis measurements were performed at $-0.24 \mathrm{~V}$ (SCE). 